\title{
HIGH PRESSURE AND HIGH TEMPERATURE EQUATION-OF-STATE OF GAMMA AND LIQUID IRON
}

\author{
GEORGE Q. CHEN * AND THOMAS J. AHRENS ** \\ *Present address: The Santa Cruz Operations, Inc., 400 Encinal Street, POB 1900, Santa Cruz, \\ CA 95061-1900 \\ **Correspondent: Lindhurst Laboratory of Experimental Geophysics, Seismological Laboratory \\ 252-21, California Institute of Technology, Pasadena, CA 91125, tja@caltech.edu
}

\section{ABSTRACT}

Shock-wave experiments on pure iron preheated to $1573 \mathrm{~K}$ were conducted in the 17-73 GPa range. The shock-wave equation of state of $\gamma$-iron at an initial temperature of $1573 \mathrm{~K}$ can be fit with $\mathrm{u}_{\mathrm{s}}=4.102(0.015) \mathrm{km} / \mathrm{s}+1.610(0.014) \mathrm{u}_{\mathrm{p}}$ with $\rho_{\mathrm{o}}=7.413 \pm 0.012 \mathrm{Mg} / \mathrm{m}^{3}$. We obtain for $\gamma$-iron's bulk modulus and pressure derivative the values: $124.7 \pm 1.1 \mathrm{GPa}$ and $5.44 \pm 0.06$, respectively.

We present new data for sound velocities in the $\gamma$ - and liquid-phases. In the $\gamma$-phase, to a first approximation, the longitudinal sound velocity is linear with respect to density: $V_{p}=-3.13$ $(0.72)+1.119(0.084) \rho$ (units for $V_{p}$ and $\rho$ are $\mathrm{km} / \mathrm{s}$ and $\mathrm{Mg} / \mathrm{m}^{3}$, respectively). Melting was observed in the highest pressure (about 70-73 GPa) experiments at a calculated shock temperature of $2775 \pm 160 \mathrm{~K}$. This result is consistent with a previously calculated melting curve (for $\varepsilon$-iron) which is close to those measured by Boehler [1] and Saxena et al. [2]. The liquid iron sound velocity data yields a Grüneisen parameter value of $1.63 \pm 0.28$ at $9.37 \pm 0.02 \mathrm{Mg} / \mathrm{m}^{3}$ at $71.6 \mathrm{GPa}$. The quantity $\gamma \rho$ is $15.2 \pm 2.6 \mathrm{Mg} / \mathrm{m}^{3}$, which agrees with the uncertainty bounds of Brown and McQueen [3] (13.3-19.6 Mg/m 3 . Based on upward pressure and temperature extrapolation of the melting curve of $\gamma$-iron, the estimated inner core-outer core boundary temperature is $5500 \pm 400 \mathrm{~K}$, the temperature at the core-mantle boundary on the outer core side is $3930 \pm 630 \mathrm{~K}$.

\section{INTRODUCTION}

Motivated by the importance of the behavior of molten iron, the major constituent of the outer core of the Earth, and the belief that the melting temperature of iron at the pressure of molten outer-core-solid inner-core boundary ( $330 \mathrm{GPa}$ ) represents a fixed temperature point within the Earth, Brown and McQueen conducted pioneering measurements of the longitudinal wave velocity behind shock waves along the principal Hugoniot (Fig. 1) of iron. They interpreted the 5 and $3.5 \%$ decreases in compressional wave velocity at 200 and $243 \mathrm{GPa}$ as the intersection of the Hugoniot with the $\varepsilon$ to $\gamma$, and $\gamma$ to liquid phase lines. Assumption dependent temperature calculations gave 4100 to $5300 \mathrm{~K}$ and 4900 to $6900 \mathrm{~K}$, for the 200 and $243 \mathrm{GPa}$ transitions, respectively.

More recent diamond anvil measurements of the melting point versus pressures below 200 $\mathrm{GPa}$ appeared to be discrepant (e.g. Boehler [1], Williams et al.[4]) with each other as are the extrapolations upward into the pressure regime of shock temperature measurements [4].

With the objective of measuring the melting behavior of iron below $100 \mathrm{GPa}$, this study was conducted to determine the Hugoniot equation-of-state (EOS) and the sound velocity along the $\gamma$-iron Hugoniot. These data provide independent measurement of the intersection of a high temperature Hugoniot with the melting curve of $\gamma$-iron. 


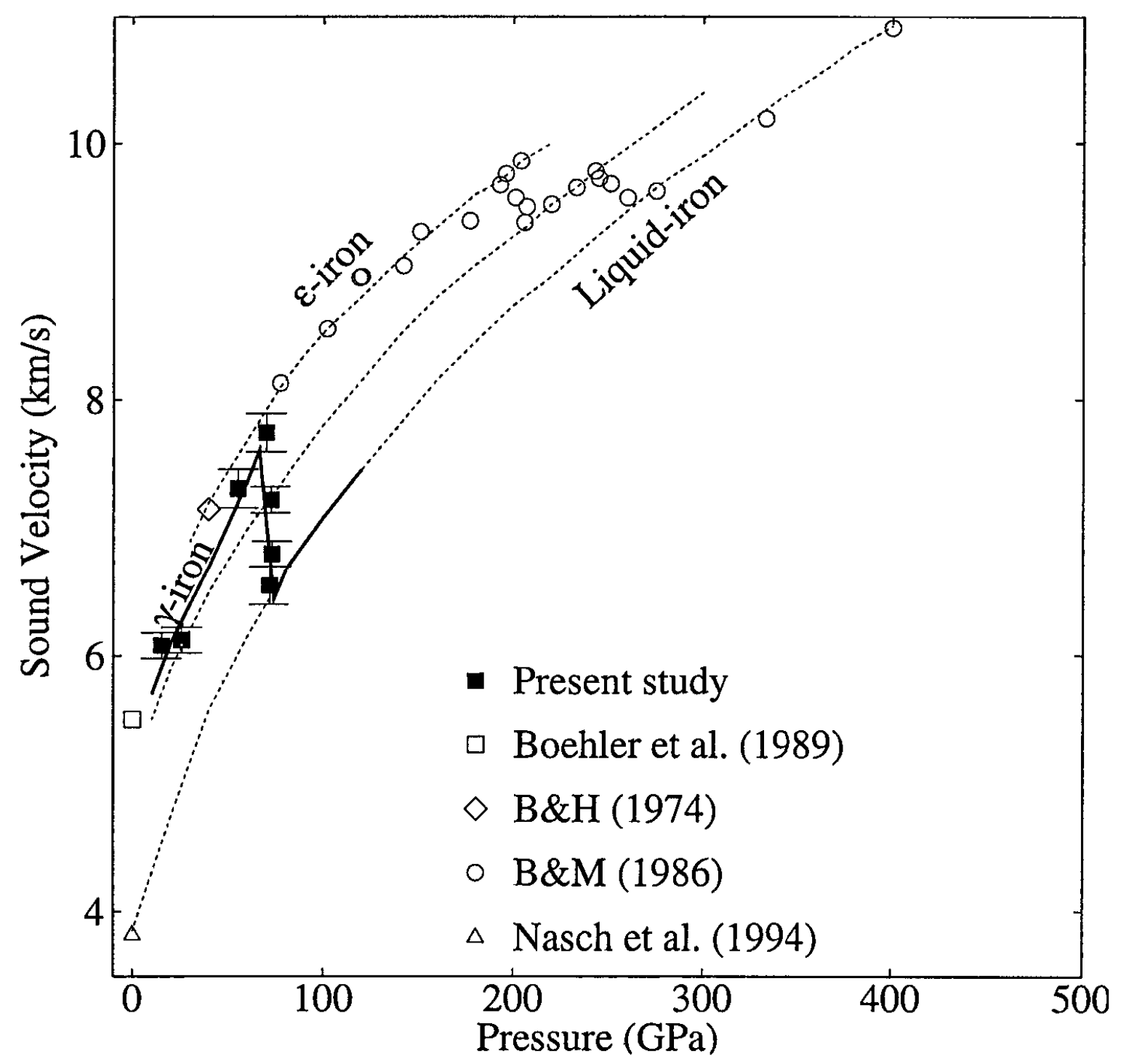

Figure 1: Sound velocity measurements. Present data indicate $\gamma$-iron melts at about $70 \pm 2 \mathrm{GPa}$. Abbreviations: B\&H: Barker and Hollenbach [5]; B\&M: Brown and McQueen [3].

\section{EXPERIMENTAL PREPARATION}

The pure iron targets are in the shape of a single machined disk, the "driver plate" is $2 \mathrm{~mm}$ thick and $38 \mathrm{~mm}$ in diameter, the central "top hat" is $4 \mathrm{~mm}$ thick and $13 \mathrm{~mm}$ in diameter [6]. The target is heated via an induction coil (see Chen and Ahrens [6]) placed around the top hat. The temperature is monitored until just before impact with a two-color infrared pyrometer (Williamson 8120 S-C-WD2) which in turn was calibrated against a thermocouple (Figure 2).

Two dual-color pyrometers (Williamson $8120 \mathrm{~S}-\mathrm{C}-\mathrm{WD} 2$ (temperature range: $1000-$ $2000^{\circ} \mathrm{C}$ ), and Ircon R-20C10-0-0-0-00-0/000) were used in the experiments. These were calibrated in a Deltech furnace using a Pt-Pt/10\%Rh thermocouple as a standard. The pure iron target was placed in a mixture of $\mathrm{CO}_{2}$ and $\mathrm{H}_{2}$ gas. The iron was thus stable in a the temperature range of the measurements (1306-1673 K measured by the thermocouple data), except when the target was deliberately oxidized to observe the effect of surface oxidation on thermal radiation 
detected by the pyrometer. The thermocouple was calibrated at melting point of gold $(1337.4 \mathrm{~K})$ and was found to read $2.7 \mathrm{~K}$ low. The accuracy of the thermocouple is estimated $\pm 1 \mathrm{~K}$.

Several factors that may contribute to errors in the pyrometer temperature were investigated during the calibrations, including non-normal pyrometer viewing angle, surface oxidation, and IR absorption of $\mathrm{CO}_{2}$ in gas flow (through which the samples were observed by the pyrometers). Systematic errors in the pyrometer data, may result from incomplete knowledge of the IR transmission and reflection properties of windows and mirrors in the pyrometer light path. The last two factors were found to be the major causes of uncertainty. Thin quartz or Pyrex windows

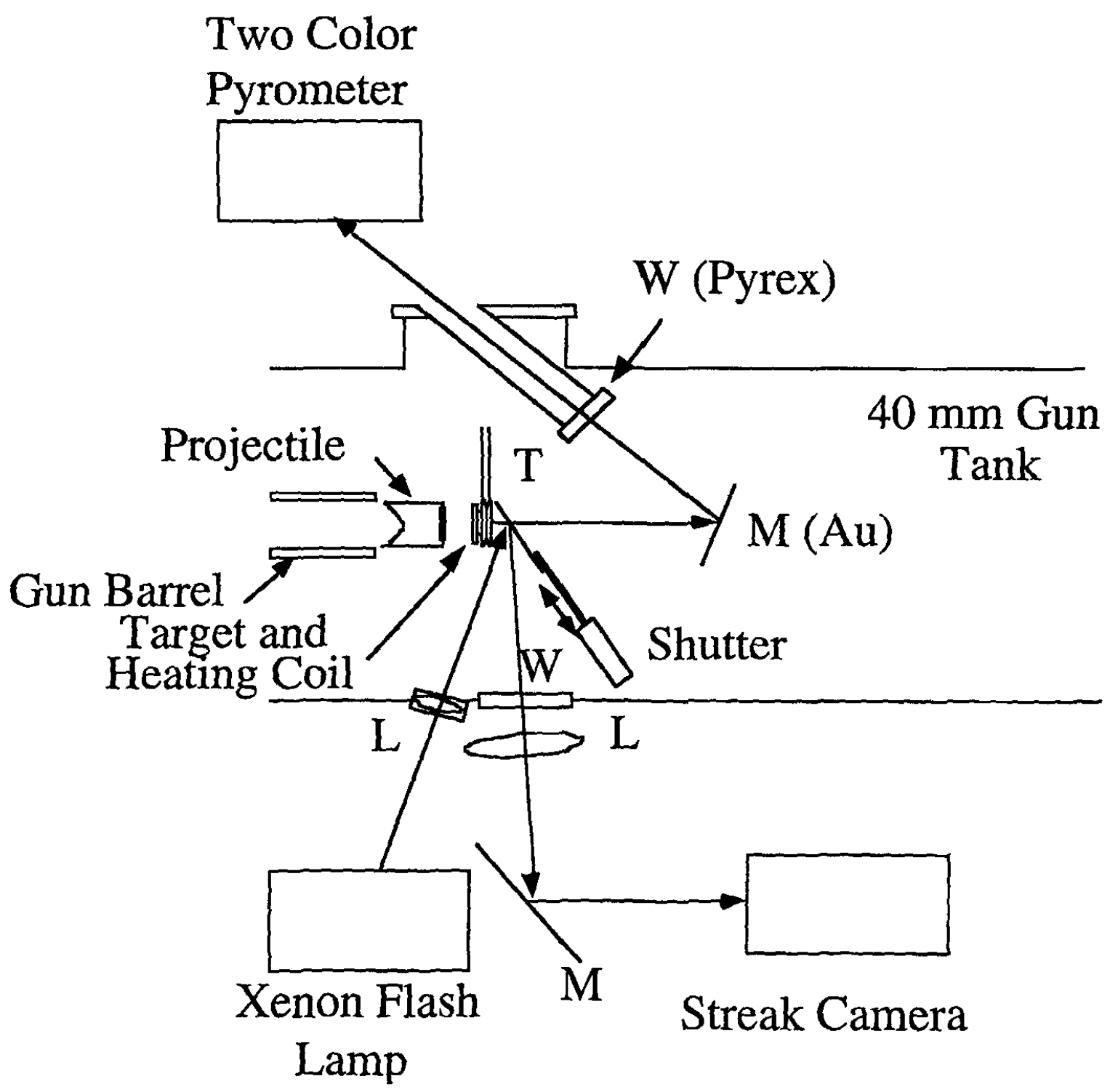

Figure 2. Experimental assemblies for EOS experiments. Iron target is preheated with RF induction coils and temperature is monitored by pyrometer. Abbreviations: W: window; L: lens; M: mirror; $\mathrm{M}(\mathrm{Au})$ : gold mirror; T: EOS turning mirror. About 1 second before launching projectile, EOS turning mirror is inserted in front of the target free-surface via a compressed airoperated piston [7]. 
Table I: Hugoniot data for $\gamma$-iron centered at $1573 \mathrm{~K}$ (initial density is $7.413 \pm 0.012 \mathrm{Mg} / \mathrm{m}^{3}$ )

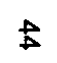

\begin{tabular}{|c|c|c|c|c|c|c|c|c|c|c|}
\hline \multirow[b]{2}{*}{ Shot } & \multicolumn{3}{|c|}{ Flyer Plate } & \multicolumn{2}{|c|}{$\begin{array}{c}\text { Fe Sample } \\
\text { Thicknesses }\end{array}$} & \multirow{2}{*}{$\begin{array}{l}\text { Shock } \\
\text { Velocity } \\
(\mathrm{km} / \mathrm{s})\end{array}$} & \multirow{2}{*}{$\begin{array}{l}\text { Particle } \\
\text { Velocity } \\
(\mathrm{km} / \mathrm{s})\end{array}$} & \multirow[b]{2}{*}{$\begin{array}{c}\text { Pressure } \\
(\mathrm{GPa})\end{array}$} & \multirow[b]{2}{*}{$\begin{array}{l}\text { Density } \\
\left(\mathrm{Mg} / \mathrm{m}^{3}\right)\end{array}$} & \multirow{2}{*}{$\begin{array}{c}\text { Shock } \\
\text { Temperature } \\
\text { (K) }\end{array}$} \\
\hline & Material & $\begin{array}{l}\text { Thickness } \\
\text { (mm) }\end{array}$ & $\begin{array}{c}\text { Impact Velocity } \\
(\mathrm{km} / \mathrm{s})\end{array}$ & $\begin{array}{l}\text { Driver } \\
(\mathrm{mm})\end{array}$ & $\begin{array}{l}\text { Total } \\
\text { (mm) }\end{array}$ & & & & & \\
\hline 946 & $\overline{\mathrm{Al}}$ & $\begin{array}{c}2.731 \\
(0.003)\end{array}$ & $\begin{array}{c}1.432 \\
(0.005)\end{array}$ & $\begin{array}{c}1.953 \\
(0.008)\end{array}$ & $\begin{array}{c}5.925 \\
(0.002)\end{array}$ & $\begin{array}{c}4.873 \\
(0.009)\end{array}$ & $\begin{array}{c}0.482 \\
(0.002)\end{array}$ & $\begin{array}{l}17.4 \\
(0.1)\end{array}$ & $\begin{array}{c}8.246 \\
(0.005)\end{array}$ & $\begin{array}{l}1883 \\
(69)\end{array}$ \\
\hline 944 & $\mathrm{Ta}$ & $\begin{array}{l}2.794 \\
(0.003)\end{array}$ & $\begin{array}{c}1.574 \\
(0.006)\end{array}$ & $\begin{array}{c}1.988 \\
(0.018)\end{array}$ & $\begin{array}{c}5.950 \\
(0.003)\end{array}$ & $\begin{array}{c}5.717 \\
(0.020)\end{array}$ & $\begin{array}{c}0.974 \\
(0.004)\end{array}$ & $\begin{array}{l}41.4 \\
(0.2)\end{array}$ & $\begin{array}{c}8.957 \\
(0.011)\end{array}$ & $\begin{array}{l}2272 \\
(142)\end{array}$ \\
\hline 978 & $\overline{\mathrm{Ta}}$ & $\begin{array}{c}5.161 \\
(0.003)\end{array}$ & $\begin{array}{l}1.976 \\
(0.006)\end{array}$ & $\begin{array}{c}1.976 \\
(0.004)\end{array}$ & $\begin{array}{c}5.966 \\
(0.003)\end{array}$ & $\begin{array}{c}5.940 \\
(0.026)\end{array}$ & $\begin{array}{c}1.220 \\
(0.004)\end{array}$ & $\begin{array}{l}53.9 \\
(0.2)\end{array}$ & $\begin{array}{c}9.354 \\
(0.017)\end{array}$ & $\begin{array}{l}2445 \\
(176)\end{array}$ \\
\hline 992 & $\mathrm{Ta}$ & $\begin{array}{c}2.649 \\
(0.003)\end{array}$ & $\begin{array}{c}2.146 \\
(0.007)\end{array}$ & $\begin{array}{c}2.054 \\
(0.003)\end{array}$ & $\begin{array}{c}6.099 \\
(0.003)\end{array}$ & $\begin{array}{c}6.255 \\
(0.010)\end{array}$ & $\begin{array}{c}1.311 \\
(0.005)\end{array}$ & $\begin{array}{l}60.9 \\
(0.2)\end{array}$ & $\begin{array}{c}9.401 \\
(0.012)\end{array}$ & $\begin{array}{l}2607 \\
(145)\end{array}$ \\
\hline 980 & $\mathrm{Ta}$ & $\begin{array}{l}2.720 \\
(0.003)\end{array}$ & $\begin{array}{l}2.230 \\
(0.007)\end{array}$ & $\begin{array}{c}2.087 \\
(0.003)\end{array}$ & $\begin{array}{c}6.099 \\
(0.002)\end{array}$ & $\begin{array}{c}6.149 \\
(0.040)\end{array}$ & $\begin{array}{c}1.375 \\
(0.006)\end{array}$ & $\begin{array}{l}62.8 \\
(0.3)\end{array}$ & $\begin{array}{c}9.567 \\
(0.026)\end{array}$ & $\begin{array}{l}2643 \\
(149)\end{array}$ \\
\hline 989 & $\mathrm{Ta}$ & $\begin{array}{r}2.756 \\
(0.003) \\
\end{array}$ & $\begin{array}{c}2.378 \\
(0.008) \\
\end{array}$ & $\begin{array}{c}2.057 \\
(0.030) \\
\end{array}$ & $\begin{array}{r}6.022 \\
(0.005) \\
\end{array}$ & $\begin{array}{c}6.364 \\
(0.022) \\
\end{array}$ & $\begin{array}{c}1.457 \\
(0.006) \\
\end{array}$ & $\begin{array}{l}69.0 \\
(0.3) \\
\end{array}$ & $\begin{array}{c}9.650 \\
(0.017) \\
\end{array}$ & $\begin{array}{l}2767 \\
(161)\end{array}$ \\
\hline 945 & $\mathrm{Ta}$ & $\begin{array}{c}2.751 \\
(0.003)\end{array}$ & $\begin{array}{c}2.513 \\
(0.010)\end{array}$ & $\begin{array}{c}1.980 \\
(0.006)\end{array}$ & $\begin{array}{c}5.888 \\
(0.003)\end{array}$ & $\begin{array}{c}6.527 \\
(0.020)\end{array}$ & $\begin{array}{c}1.537 \\
(0.007)\end{array}$ & $\begin{array}{l}74.4 \\
(0.4)\end{array}$ & $\begin{array}{c}9.733 \\
(0.018)\end{array}$ & $\begin{array}{l}2820 \\
(161)\end{array}$ \\
\hline
\end{tabular}

1. Room temperature.

2. Uncertainties include experimental measurements and calculations. 
and gold mirrors can greatly reduce errors of the last type. Corrections for residual errors were made to the pre-shock temperatures of the shock-wave experiments. To summarize, the pyrometers were able to determine the sample temperature to within about $10 \mathrm{~K}$ after thermocouple calibration.

The spatial variations in temperature in target is estimated and measured to be about $52 \mathrm{~K}$ at a pre-shock temperature of $1573 \mathrm{~K}$ [6].

The experiments are of two types: EOS and VISAR. Detailed descriptions of the two types of experiments can be found in Miller et al [8] and Duffy and Ahrens [9], respectively. Experimental results are summarized in the following section.

\section{EOS EXPERIMENTS AT $1573 \mathrm{~K}$}

These experiments have been conducted on the $40 \mathrm{~mm}$ propellant gun at Caltech in the 17$74 \mathrm{GPa}$ range (Figure 2, Table I). The equation of state experiments monitor optical reflectivity on the polished (stepped) back surface of the target which decreases rapidly upon shock arrival. In conducting the experiments we determine initial density (using the measurement of initial temperature and iron's density-temperature relationship [10]), the shock-wave and projectile velocity, and derived are: particle velocity, shock pressure and the high pressure specific volume by the impedance matching method. The properties of the impactor materials and data sources are given in Table II.

Table II: Equation of states of flyer plate materials

\begin{tabular}{c|c|c|c}
\hline Material & $\rho_{0}\left(\mathrm{Mg} / \mathrm{m}^{3}\right)$ & $c_{0}(\mathrm{~km} / \mathrm{s})$ & $\mathrm{s}$ \\
\hline $\mathrm{Ta}^{1}$ & 16.650 & 3.293 & 1.307 \\
& $(0.03)$ & $(0.005)$ & $(0.025)$ \\
\hline $\mathrm{Al} \mathrm{2024^{2 }}$ & 2.784 & 5.330 & 1.34 \\
& $(0.005)$ & $(0.050)$ & $(0.02)$ \\
\hline $\mathrm{Al}^{2}$ & 2.683 & 5.349 & 1.34 \\
6061 & $(0.003)$ & $(0.056)$ & $(0.20)$ \\
\hline
\end{tabular}

1. [11]

2. [12]

The results are plotted in Figures 3 and 4. Although melting may have occurred in the highest pressure experiments, all the $u_{s}-u_{p}$ data can be fit with a linear function:

$$
u_{s}=4.102(0.015) \mathrm{km} / \mathrm{s}+1.610(0.014) u_{p} \text {. }
$$

For reference, the principal $u_{s}-u_{p}$ relationship for $\alpha$-iron shocked into the $\varepsilon$ phase is [13]:

$$
u_{s}=3.955(0.028) \mathrm{km} / \mathrm{s}+1.58(0.011) \mathrm{u}_{\mathrm{p}} \text {, }
$$

with an initial density of $7.850 \mathrm{Mg} / \mathrm{m}^{3}$ (for $\alpha$-iron at STP).

With initial density at $1573 \mathrm{~K}$ of $7.413(0.012) \mathrm{Mg} / \mathrm{m}^{3}[10]$ (the uncertainty is estimated from the pre-shock temperature uncertainty of about $52 \mathrm{~K}[6]$ ), and using the relations between $\mathrm{c}_{0}$, $s$ and $\mathrm{K}_{\mathrm{os}}, \mathrm{K}_{\mathrm{os}}^{\prime}[14]$,

$$
\begin{aligned}
\mathrm{K}_{\mathrm{os}} & =\rho_{0} \mathrm{c}^{2}, \\
\mathrm{~K}^{\prime}{ }_{\text {os }} & =4 \mathrm{~s}-1,
\end{aligned}
$$


the $u_{s}-u_{p}$ relation gives

$$
\mathrm{K}_{\mathrm{os}}^{1573 \mathrm{~K}}=124.7(1.1) \mathrm{GPa} \text {, }
$$

and

$$
\mathrm{K}_{\text {os }}^{\prime}=5.44(0.06)
$$

for $\gamma$-iron. We note that equations 3 and 4 assume the Murnaghan relation [14].

\section{SOUND VELOCITY MEASUREMENTS AT $1573 \mathrm{~K}$}

The VISAR (Velocity Interferometer System for Any Reflector, Figure 5) [15] uses a modified Michaelson interferometer to measure the Doppler-shift of a laser beam reflected from the surface of the moving target.

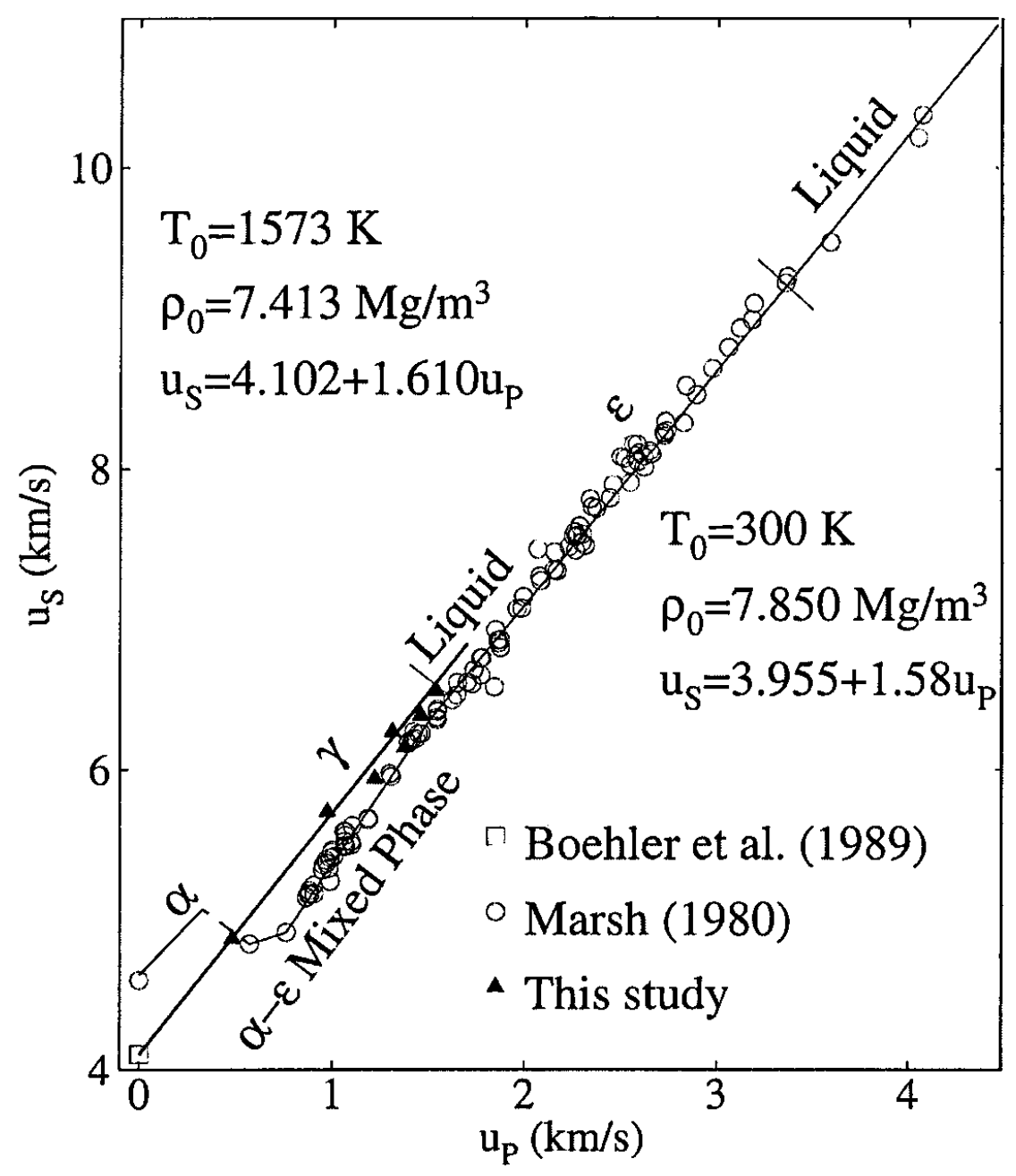

Figure 3. $u_{s}-u_{p}$ relation for high temperature $(1573 \mathrm{~K})$ iron (heavy solid line). The principal Hugoniot [5] (light solid line) is shown for comparison. The dashed line between the $\alpha$-phase and the mixed phase indicate states not achievable experimentally. 


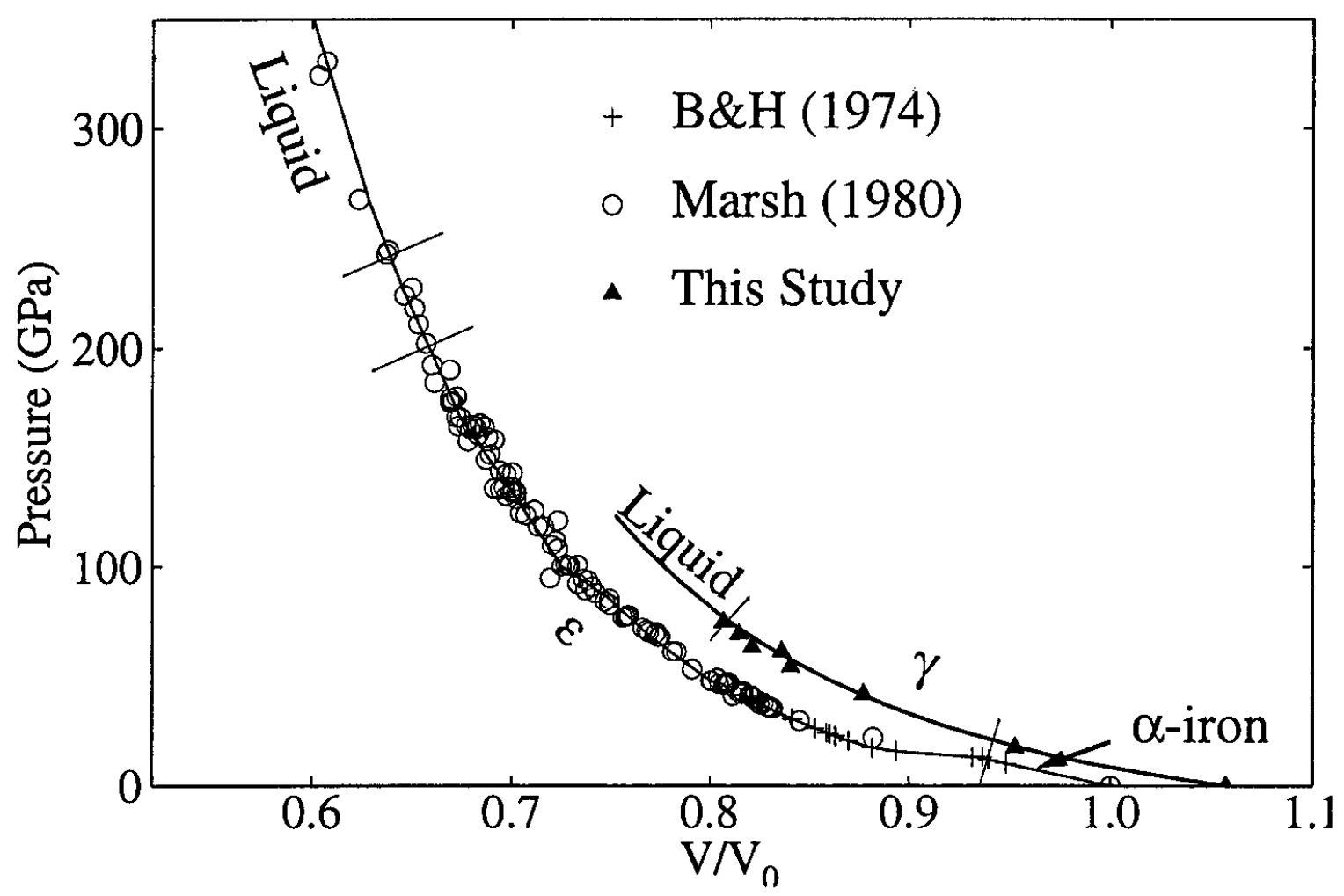

Figure 4. High temperature, $\gamma$-iron $(1573 \mathrm{~K})$ Hugoniot (heavy line) of this study compared to $\alpha$-iron principal Hugoniot $[12 ; 16]$. Specific volume is normalized to that of iron at STP $V_{0}$. B\&H Refers to [5].

The relationship between the reflector velocity, $u$, and the fringe count, $F$, is given by [15]:

$$
\mathrm{u}(\mathrm{t}-\tau / 2)=\mathrm{kF}(\mathrm{t}) \text {, }
$$

where $\mathrm{k}$ is the fringe constant. Here $\mathrm{k}$ as given by [5] is:

$$
\mathrm{k}=\frac{\lambda_{0}}{2 \tau\left(1+\Delta \mathrm{v} / \mathrm{v}_{0}\right)(1+\delta)}
$$

where, the incident laser wavelength, $\lambda_{0}=514.5 \mathrm{~nm},(1+\delta)$ is a correction term related to dispersion in the etalons, and $\left(1+\Delta v / v_{0}\right)$ is a correction term that accounts for the change in the reflective index of the shock-compressed window material [16]. For our experiments where windows are not used, this term is unity. The value of $(1+\delta)$ has been determined [5] to be 1.0339 at $\lambda=514.5 \mathrm{~nm}$. The delay time $\tau$ is determined from: 


$$
\tau=\frac{2 h}{c}\left(n-\frac{1}{n}\right)
$$

where $\mathrm{h}=189.92 \mathrm{~mm}$ is the etalon thickness, $\mathrm{n}=1.468 \pm 0.003$ [17] is the etalon refractive index, and $\mathrm{c}$ is the speed of light. From Equations 8 and 9, the fringe constant is determined to be 225 $\mathrm{m} / \mathrm{s} /$ fringe.

In the present experiments the free-surface of the iron target or the molybdenum cap accelerates upon shock arrival. It then decelerates when the release wave from the back of the flyer plate has propagated to the free-surface. The initial release velocity (that propagates forward at the compressional wave velocity in solids and the bulk sound velocity in liquids) in shock compressed $\gamma$ - or molten-iron is calculated from the time interval between the acceleration and deceleration of the free-surface. The arrangement is modified from Duffy and Ahrens [9] for the present high temperature environment.

Difficulties with high temperature iron VISAR experiments include:

1. The surface of iron samples suffers adverse alteration under high temperature and high pressure; there are a number of possible causes:

(a) Oxidation during heating. In the typical vacuum in the gun tank $(\sim 100 \mu \mathrm{m} \mathrm{Hg})$, iron rapidly oxidizes.

(b) The $\alpha$ - to $\gamma$-phase transition at $1196 \mathrm{~K}$ changes the surface texture of the sample.

To counter these problems, we used a $0.5 \mathrm{~mm}$ thick molybdenum cap on the rear surface of the iron as the diffuse VISAR reflector, and bled a reducing gas near the target (Figures 6 and 7). Mo, with its higher melting point at $1 \mathrm{bar}$ and being less oxidation prone, is a better VISAR reflector than iron.

2. Different thermal expansions of the metal sample and the ceramic target holder can crack the ceramic or change target position at $1573 \mathrm{~K}$. We used belleville washers in the target fixture (Figure 6) to maintain a constant compression force (about 7 newtons) squeezing the ceramic holder and the iron-molybdenum target together.

3. Radiant heating from the target would rapidly deform the plastic lens used in VISAR fiber optical probes. We used heat resistant mirrors and high temperature glass (for high temperature sources, see caption of Figure 7) in front of the probe. We also mounted the probe assembly on the aim of a compressed air-driven piston [7] to retract the probe during heating. We tested the VISAR signal reflected from iron at $1573 \mathrm{~K}$ before launching the projectile. We also split off about $10 \%$ of the reflected laser to monitor the reflected light intensity change upon shock arrival at the Mo free surface.

4. Usually it is advantageous to have a window attached to the surface at which the particle velocity is recorded with the VISAR. Although the window is generally not a perfect impedance

match with the target and causes partial release or reshock, the target adjacent to it will partially maintain the high pressure state and the arrival of forward rarefaction wave would induce a more pronounced particle velocity decrease. However, among the most common used window materials, $\mathrm{LiF}$ has a melting point of $1118 \mathrm{~K}$ [18], too low for our preheated experiments. Sapphire $\left(\mathrm{Al}_{2} \mathrm{O}_{3}\right)$ has a higher melting point $(2288 \mathrm{~K}$ [18]) and is an excellent impedance match for Fe, but it has been found that it can not be used for VISAR experiments above $15 \mathrm{GPa}$ (for unknown reasons) [5]. Therefore, we resorted to 


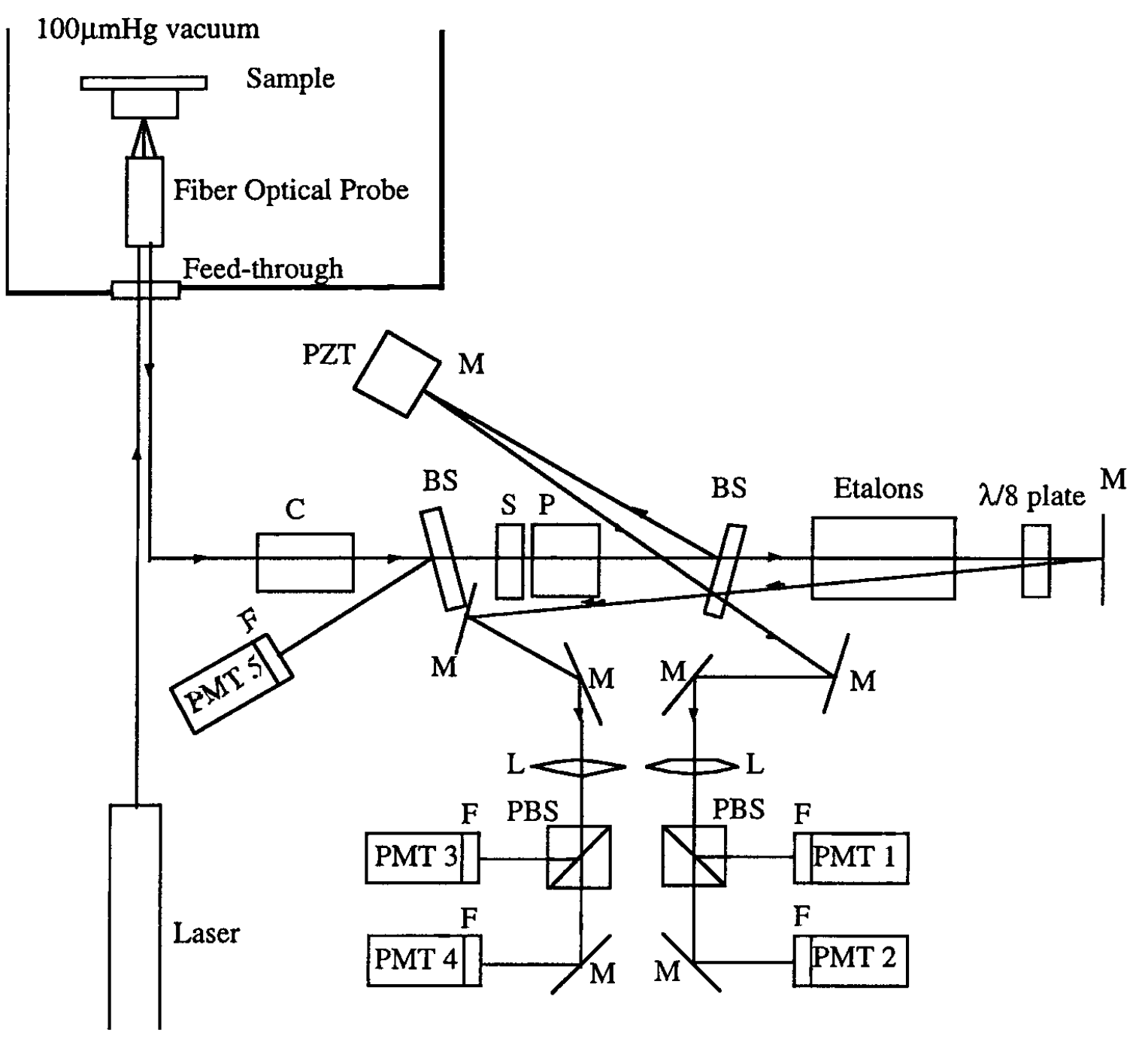

Figure 5: VISAR experimental diagram after Duffy [17]. Abbreviations are: PMT: photomultiplier tube; M: mirror; L: lens; F: Laser line filter; S: polarization scrambler; PZT: piezoelectric transducer; P: Glan-Thomson prism; BS: beam splitter; PBS: polarizing beam splitter cube. Laser is a Lexel model 95 argon ion laser.

observing velocity changes at the free surface. These changes are fairly small, but as we will discuss in the following section, they are recorded without ambiguity.

5. The digital oscilloscopes used in the experiments have recording windows of 8 , 16 and $64 \mu \mathrm{s}$; therefore, a triggering pulse shortly before the impact occurs is required to reliably trigger the oscilloscopes. In room temperature VISAR experiments, trigger pins affixed to the driver plates and pulse forming circuits serve as an oscilloscope trigger. However, trigger pins that can withstand high temperature are not now available. 


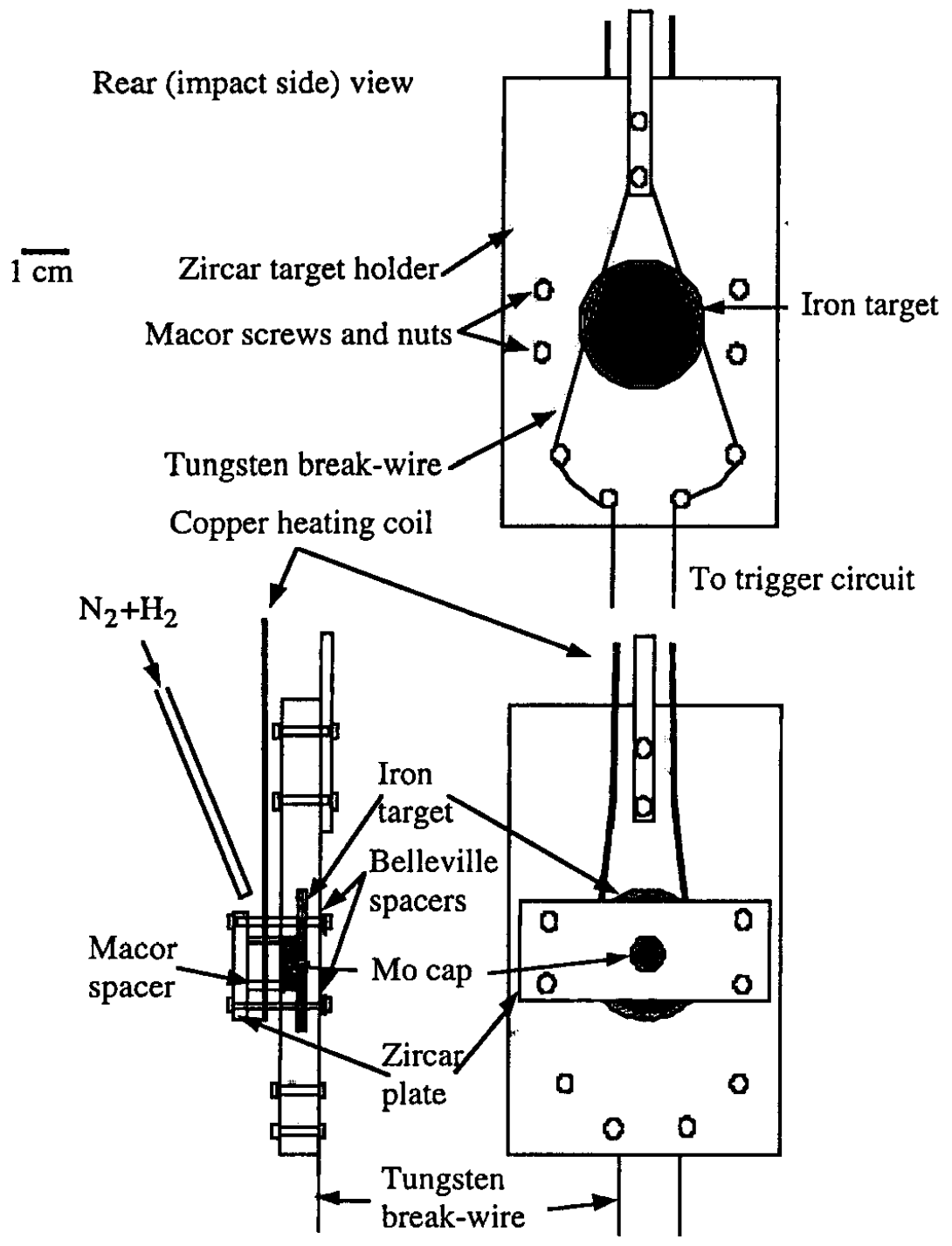

Side view

Front (detector side) view

Figure 6: Target assembly for measuring sound velocity in preheated iron. Belleville washers, McMaster-Carr, 19716K45. Break wire is tungsten, $0.076 \mathrm{~mm}$ diameter (Alfa Aesar Co., \#00457). It is clamped with slight tension with ceramic screws and nuts, flush with impact side of ceramic target holder. Distance from break wire to driver plate is $\sim 5-6 \mathrm{~mm}$.

A break-wire system (Figure 6) is found to be reliable for oscilloscope triggering in the experiments at $1573 \mathrm{~K}$. 


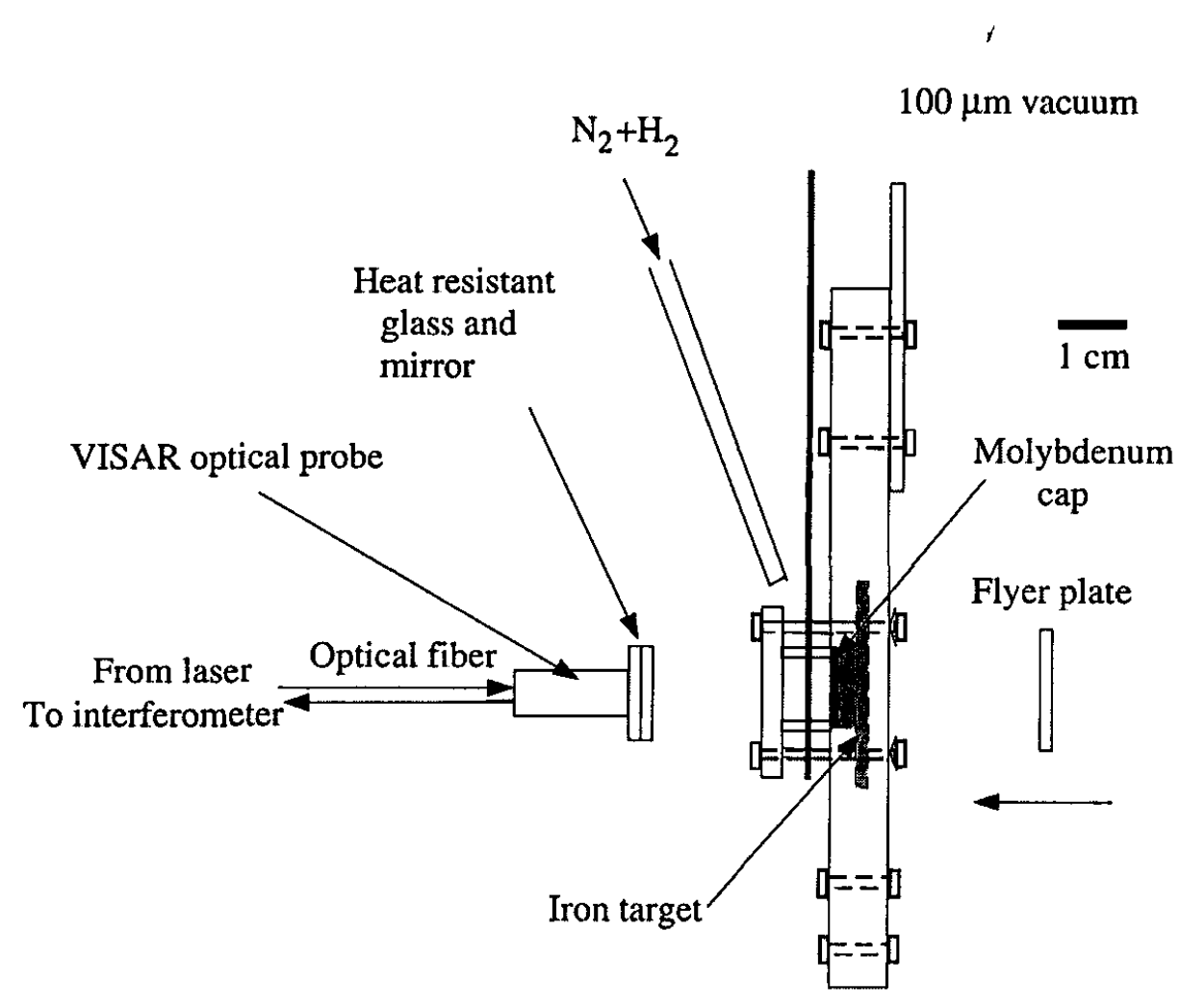

Figure 7: Experimental arrangement for conducting sound speed measurements in preheated iron. Parts are: Heat resistant glass: CVI Laser Corp., \#SKG-5-2×2, 2 mm thick; heat resistant mirror: ZC\&R extended high temperature mirror, $3.0 \mathrm{~mm}$ thick; VISAR probe: Valyn International, \#FOP-300.

\section{PHASE DETERMINATIONS}

The $1573 \mathrm{~K}$ Hugoniot in pressure-volume space is shown in Figure 4 together with the ( $\alpha$ phase) principal Hugoniot. The high-temperature Hugoniot obtained (up to $74 \mathrm{GPa}$ ) is shifted from the principal Hugoniot by a nearly constant factor (volume change due to thermal expansion and the $\alpha \rightarrow \gamma$ phase change at $1 \mathrm{bar}$, is $\sim 5.7 \%$ ). The solid-liquid transition is not prominent in the $\mathrm{P}-\mathrm{V}$ space. In general, pressure-volume equation of state experiments are not adequate for detecting melting.

The initial release wave velocity data in the material reference frame are plotted in Figure 1 as a function of shock pressure. Also plotted are previous measurements by Brown and McQueen [13] and Nasch et al. [19] for $\varepsilon$-, $\gamma$ - and liquid iron. It can be seen there is a sharp drop in sound velocity at $\sim 70 \mathrm{GPa}$, and the $72 \mathrm{GPa}$ (Shot 1008 ) datum agrees well with liquid iron data 
interpolated between Brown and McQueen [3] shock-wave data and Nasch et al. [19]'s ultrasonic data. Therefore, we infer the steep drop in sound velocity at $70 \pm 2 \mathrm{GPa}$ corresponds to the melting of $\gamma$-iron along its Hugoniot centered at $1573 \mathrm{~K}$.

We note that the present $\gamma$-iron sound velocity data lies slightly above the extrapolation of Brown and McQueen [3]'s data (the middle dashed line in Figure 3.11), as the elastic moduli usually decrease with temperature. We believe the rarefaction velocities measured corresponds to those of $\gamma$-iron because:

1. The present data set definitely start in the $\gamma$-iron field because of the initial high temperature. This portion of the phase diagram is well determined. The recently proposed $\varepsilon^{\prime}-$ phase [20] is reported to occur at about $40 \mathrm{GPa}$ and $1500 \mathrm{~K}$. However, this result has not been verified; therefore, the $\gamma$-phase is the only verified stable phase of iron in this P-T range.

2. Boehler et al. [21] measured static compressibility of $\gamma$-Fe at pressures up to $42 \mathrm{GPa}$ and temperatures between $1200-2100 \mathrm{~K}$. A fit to these data yields $\mathrm{K}_{\mathrm{OT}}=127 \mathrm{GPa}$ and $\mathrm{K}_{\mathrm{OT}}^{\prime}=2.2$. Using the density of iron at $1573 \mathrm{~K}$ and neglecting the correction from $\mathrm{K}_{\mathrm{T}}$ to $\mathrm{K}_{\mathrm{s}}$, the bulk sound velocity, $\mathrm{V}_{\mathrm{b}}$ is calculated to be $4.1 \mathrm{~km} / \mathrm{s}$. To calculate the longitudinal sound velocity of $\gamma$-iron, we require to the Poisson's ratio $v$, which has not yet been reported. We assume it is approximated by the Poisson's ratio of $\alpha$-iron at $293 \mathrm{~K}$ and 1 bar. This is calculated from the relationship between $\mathrm{V}_{\mathrm{p}}$ and the shear wave velocity $\mathrm{V}_{\mathrm{s}}$ :

$$
\mathrm{V}_{\mathrm{p}}=\mathrm{V}_{\mathrm{s}} \sqrt{\frac{2-2 \mathrm{v}}{1-2 v}}
$$

with $V_{p}=5.94$ and $V_{s}=3.26 \mathrm{~km} / \mathrm{s}[12]$, Eq. 10 gives $v=0.284$, for $\alpha$-iron. Assuming the same value for $\gamma$-iron, the longitudinal sound velocity calculated from:

$$
V_{b}=V_{p} \sqrt{\frac{1+v}{3(1-v)}}
$$

is $5.30 \mathrm{~km} / \mathrm{s}$. This value is reasonable compared to our low pressure longitudinal wave velocity datum of $6.08 \mathrm{~km} / \mathrm{s}$ at $15.2 \mathrm{GPa}$. Neglecting the difference between the Hugoniot and the isentrope, we estimate

$$
\left(\frac{\partial \mathrm{V}_{\mathrm{p}}}{\partial \mathrm{P}}\right)_{\mathrm{s}}=\frac{6.08-5.30}{15.2}=5.13 \times 10^{-2}(\mathrm{~km} / \mathrm{s} / \mathrm{GPa})
$$

for $\gamma$-iron at $1573 \mathrm{~K}$.

3. There have been several interpretations of the origin of the first $(200 \mathrm{GPa})$ velocity drop in Brown and McQueen [13]'s sound velocity data along the principal Hugoniot [1].

We suggest the $200 \mathrm{GPa}$ transition is not due to the $\varepsilon$ - to $\gamma$-phase change as Brown and McQueen [3] inferred or the melting of iron as suggested by Belonoshko [22]. Rather, it is due to the solid-solid phase change to the onset of dhcp phase [23]. 
In summary, we conclude that $\gamma$-iron shocked along a Hugoniot centered at $1573 \mathrm{~K}$ melts at $70 \pm 2 \mathrm{GPa}$. The data are consistent with termination of $\gamma$-iron at the $\sim 2900 \mathrm{~K}-90 \mathrm{GPa}$ triple point $\gamma-\varepsilon-\ell$ of Boehler (1993).

Shock temperatures of the $\gamma$-iron are calculated and plotted in Figure 8 relative to different melting curves. The major uncertainties in the shock temperature calculations arise from uncertainties in the specific heat and in the Grüneisen parameter at high pressures. The parameters used in the calculations are listed in Table III. The Grüneisen parameter of 1.73 for $\gamma$-iron at 1573 $\mathrm{K}$ and 1 bar was calculated using

$$
\gamma=\alpha \mathrm{K}_{\mathrm{T}} /\left(\rho \mathrm{C}_{\mathrm{v}}\right)
$$

This is very close to that of $\alpha$-iron (1.72) at $S T P$ (calculated from $\rho_{0}=7.850 \mathrm{Mg} / \mathrm{m}^{3}$, thermal expansion $\alpha_{0}=3.54 \times 10^{-5} \mathrm{~K}^{-1}[10], \mathrm{C}_{\mathrm{PO}}=447.3 \mathrm{~J} \mathrm{~kg}^{-1} \mathrm{~K}^{-1}$, and $\mathrm{K}_{\mathrm{OT}}=171 \mathrm{GPa}$ [24]). Previously reported values for $\alpha$-iron are 1.7 [25] and 1.69 [26]. $\mathrm{C}_{\mathrm{vo}}$ at $1 \mathrm{bar}, 1573 \mathrm{~K}$ is calculated from $\mathrm{C}_{\mathrm{PO}}$ using:

$$
\mathrm{C}_{\mathrm{vo}}=\mathrm{C}_{\mathrm{PO}} /\left(1+\alpha_{0} \gamma_{0} \mathrm{~T}\right)
$$

yielding $C_{v o}=665.7 \mathrm{~J} \mathrm{~kg}^{-1} \mathrm{~K}^{-1}$. This value is $49.1 \%$ greater than the $3 \mathrm{R}$ value. For reference, we note $C_{p}$ of $\alpha$-iron varies from $\sim 3 \mathrm{R}$ at $293 \mathrm{~K}$ to $\sim 10 \mathrm{R}$ at $1042 \mathrm{~K}$ (the Curie point) [27]. We attempted three calculations with different values of the two parameters $C_{v}$ and $\gamma$. The calculated temperatures up to $70 \mathrm{GPa}$ (the incipient melting pressure) are listed in Table IV. The temperature difference at $70 \mathrm{GPa}$ can be as large as $260 \mathrm{~K}$. However, this is probably an overestimate of uncertainty in our calculation since $C_{V}$ is unlikely to decrease to $3 R$ at high pressures. We think the temperature difference due to different $\gamma(\mathrm{V})$ functions (about $110 \mathrm{~K}$, Table IV) may be a more reasonable measure of the uncertainty in the calculation. Combining the $50 \mathrm{~K}$ uncertainty in initial temperature, we estimate the melting temperature of $\gamma$-iron at $70 \mathrm{GPa}$ to be $2775 \pm 160 \mathrm{~K}$.

Table III: Parameters for $\gamma$-iron at 1 bar, $1573 \mathrm{~K}$.

\begin{tabular}{c|l|l}
\hline$\rho_{0}\left(\mathrm{Mg} / \mathrm{m}^{3}\right)$ & $7.413(20)$ & {$[10]$} \\
\hline$\alpha_{0}\left(\mathrm{~K}^{-1}\right)$ & $6.99 \times 10^{-5}$ & [28] \\
\hline $\mathrm{C}_{0}(\mathrm{~km} / \mathrm{s})$ & $4.102(15)$ & This study \\
\hline $\mathrm{s}$ & $1.610(14)$ & This study \\
\hline $\begin{array}{c}\text { Latent heat of melting } \\
(\mathrm{J} / \mathrm{kg})\end{array}$ & $2.472 \times 10^{5}$ & {$[27]$} \\
\hline$\gamma_{0}$ & $1.73(0.18)$ & This study \\
\hline
\end{tabular}

$\gamma$-iron does not appear to super-heat when it crosses the melting point along the Hugoniot. Thus the Hugoniot, presumably, follows the melting curve between the incipient melting pressure $\mathrm{P}_{\mathrm{im}}$ to the complete melting pressure $\mathrm{P}_{\mathrm{cm}}$. To calculate $\mathrm{P}_{\mathrm{cm}}$, we assume the latent heat of melting $\Delta \mathrm{H}$ at high pressure equals its value at $1 \mathrm{bar}$ (Table III). We first calculated Hugoniot temperature of $\gamma$-iron to above the melting curve without taking into account the effect of melting, i.e., the temperature of a hypothetical metastable $\gamma$-phase. Complete melting occurs at a $P_{\mathrm{cm}}$ such that: 


$$
\Delta S\left(P_{c m}\right)=\int_{T_{m}\left(P_{c m}\right)}^{T_{H}}, \frac{C_{V} d T}{T}
$$

where $T_{m}\left(P_{c m}\right)$ and $T_{H}$ are melting point and the metastable Hugoniot temperature at $P_{c m}$, respectivẹly, and

$$
\Delta S\left(P_{c m}\right)=\frac{\Delta H}{T_{m}\left(P_{c m}\right)}
$$

is the entropy change associated with melting at $\mathrm{P}_{\mathrm{cm}}$. Using $\mathrm{C}_{\mathrm{v}}=\mathrm{C}_{\mathrm{vo}}$ for $\gamma$-iron, we obtained $\mathrm{P}_{\mathrm{cm}}$ $=86.4 \mathrm{GPa}$. Instead, assuming the entropy increase associated with melting is constant yields $\mathrm{P}_{\mathrm{cm}}$ $=104.2 \mathrm{Gpa}$. Averaging these estimates yields $95 \mathrm{GPa}$, since the Hugoniot lies along, or slight above the $\gamma-\varepsilon-\ell$ triple point, the temperatures once pressures are consistant with those of Boehler, 1993.

We conclude that $\gamma$-iron shocked from initial temperature of $1573 \mathrm{~K}$ is in the liquid field at $70 \mathrm{GPa}$ and $2775 \mathrm{~K}$ is also consistent with the phase diagram proposed by Saxena et al. [29]. Iron's phase diagram with present uncertainties of the phase boundaries is shown in Figure 9. Compared with the phase diagram suggested by Brown and McQueen [30], the melting curve is lowered by about $500 \mathrm{~K}$ at $243 \mathrm{GPa}$, and the $\beta$-phase (possibly in the dhcp structure) replaces the previously suggested $\gamma$ stability regime above $70 \mathrm{GPa}$.

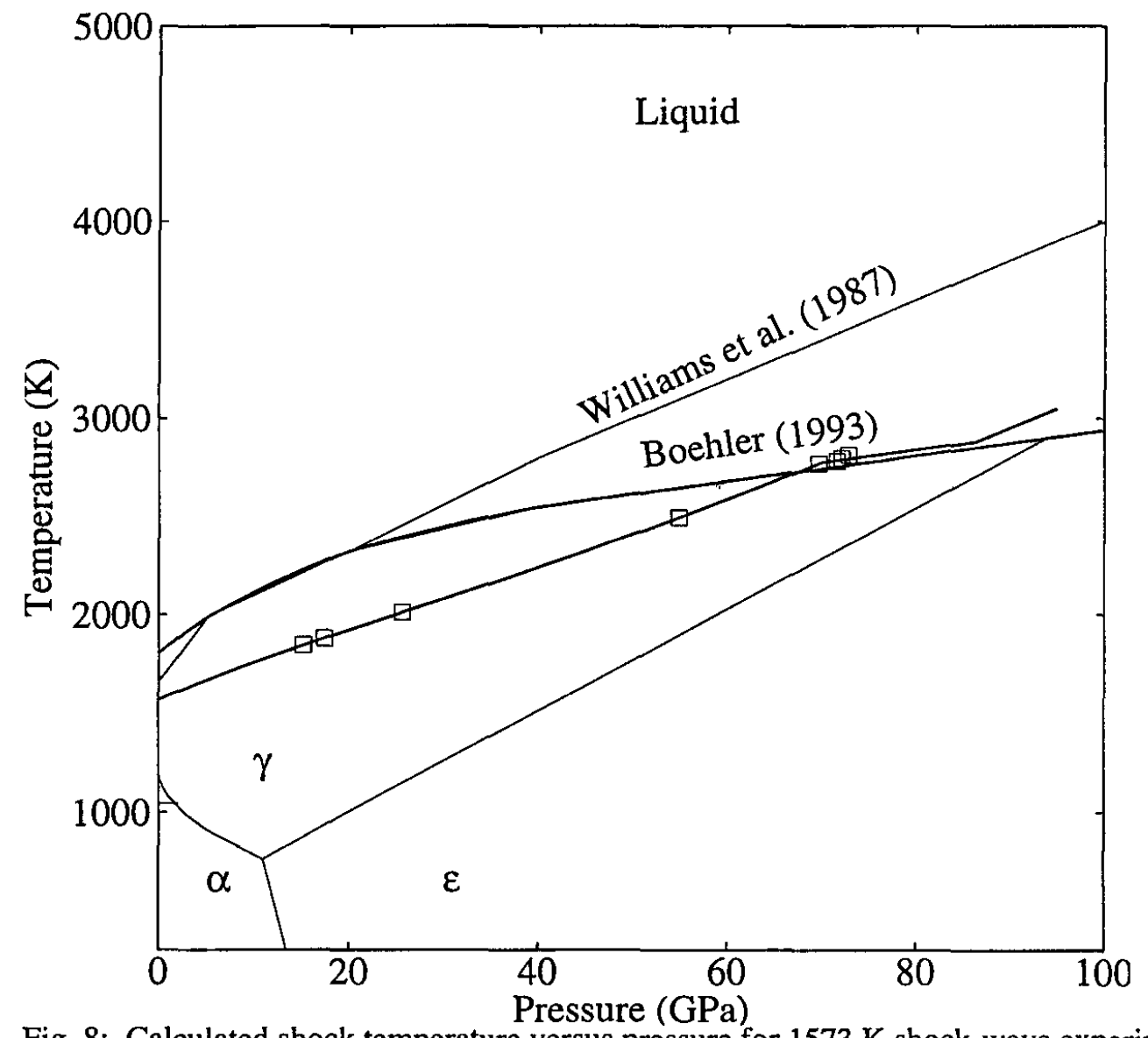

Fig. 8: Calculated shock temperature versus pressure for $1573 \mathrm{~K}$ shock-wave experiments on iron and previous diamond anvil melting data.. 


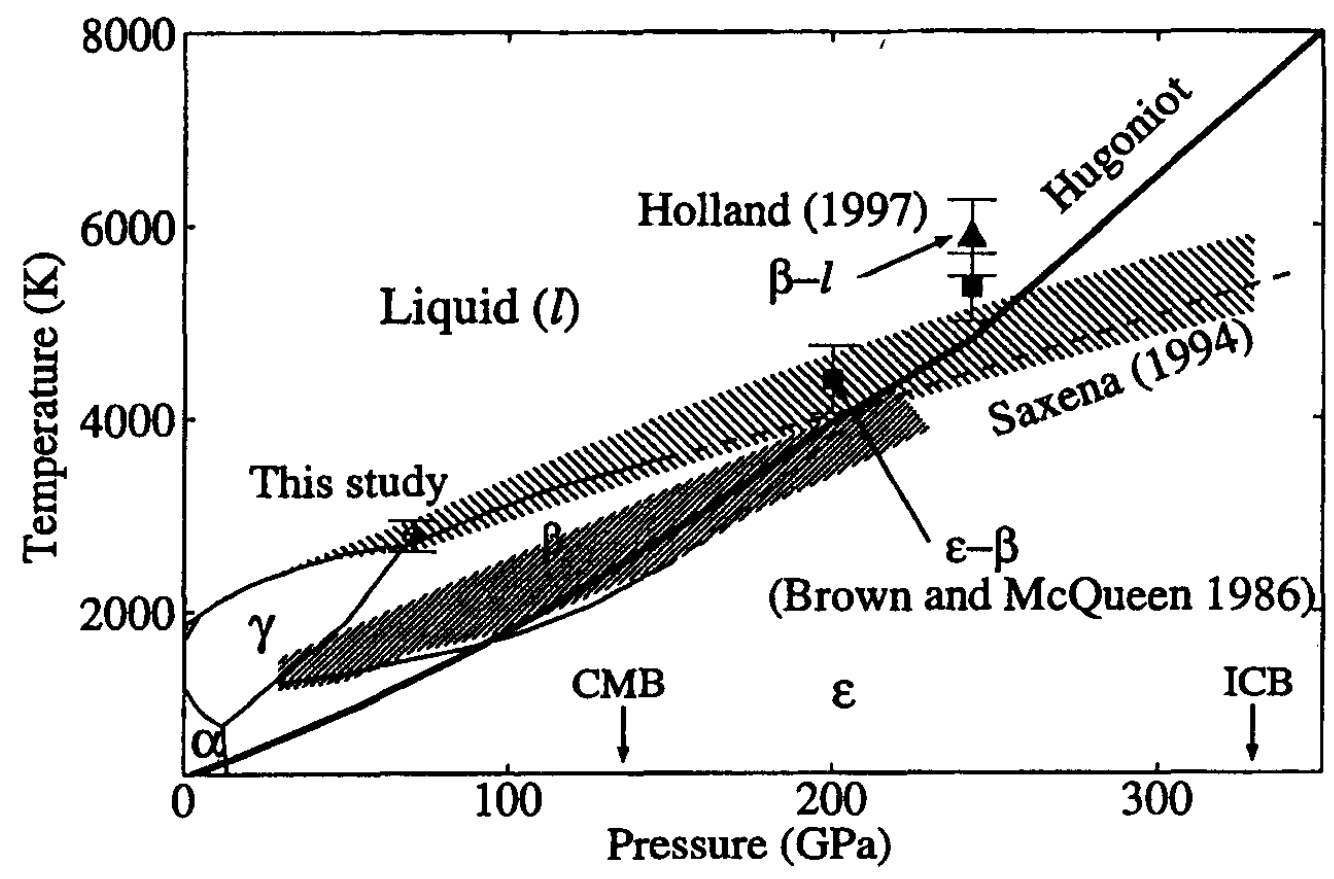

Figure 9: Several proposed phase lines on phase diagram of iron. Hachured bands represent uncertainties of phase boundaries. We propose that the Hugoniot crosses the $\varepsilon-\beta$ phase boundary at $200 \mathrm{GPa}$, and the $\beta$-liquid phase boundary at $243 \mathrm{GPa}$. Solid triangle is Holland [31]'s temperature measurement of $\beta$-liquid transition; Two solid squares are Brown and McQueen [3]'s calculated shock temperatures for what they proposed to be the $\varepsilon$ to $\gamma$ and $\gamma$ to liquid transitions. These are suggested rather, to be $\varepsilon$ to $\beta$ and $\beta$ to liquid.

In Figure 10, we also plot the longitudinal velocity as a function of density for $\gamma$-iron. Our data and the datum calculated from Boehler et al. [21] indicate that, to a first approximation, the longitudinal sound velocity for $\gamma$-iron is linear with respect to density. The linear fit is:

$$
\mathrm{V}_{\mathrm{p}}=-3.13(0.72)+1.119(0.084) \rho
$$

with $V_{p}$ in $\mathrm{km} / \mathrm{s}$ and $\rho$ in $\mathrm{Mg} / \mathrm{m}^{3}$. Similar results for the bulk sound velocity of lead [32] are reported.

Table IV: Calculated shock temperature of $\gamma$-iron initially at $1573 \mathrm{~K}$ from three plausible models where, $\gamma_{0}=1.73$. 


\begin{tabular}{c|c|c|c}
\hline \multirow{2}{*}{$\begin{array}{c}\text { Pressure } \\
(\mathrm{GPa})\end{array}$} & \multicolumn{3}{|c}{ Shock Temperature $(\mathrm{K})$} \\
\cline { 2 - 4 } & $\begin{array}{c}\gamma \rho=\text { const. } \\
\mathrm{C}_{\mathrm{v}}=\mathrm{C}_{\mathrm{v}}\end{array}$ & $\begin{array}{c}\gamma \rho=\text { const. } \\
\mathrm{C}_{\mathrm{v}}=3 \mathrm{R}\end{array}$ & $\begin{array}{c}\gamma=\text { const. } \\
\mathrm{C}_{\mathrm{v}}=\mathrm{C}_{\mathrm{v}}\end{array}$ \\
\hline $10-4$ & 1573 & 1573 & 1573 \\
\hline 5 & 1673 & 1673 & 1675 \\
\hline 10 & 1763 & 1765 & 1769 \\
\hline 15 & 1845 & 1852 & 1858 \\
\hline 20 & 1924 & 1939 & 1945 \\
\hline 25 & 2002 & 2038 & 2031 \\
\hline 30 & 2081 & 2121 & 2129 \\
\hline 35 & 2160 & 2218 & 2207 \\
\hline 40 & 2241 & 2319 & 2298 \\
\hline 45 & 2323 & 2425 & 2390 \\
\hline 50 & 2409 & 2536 & 2485 \\
\hline 55 & 2457 & 2653 & 2581 \\
\hline 60 & 2587 & 2774 & 2680 \\
\hline 65 & 2681 & 2900 & 2781 \\
\hline 70 & 2275 & 3032 & 2884 \\
\hline
\end{tabular}

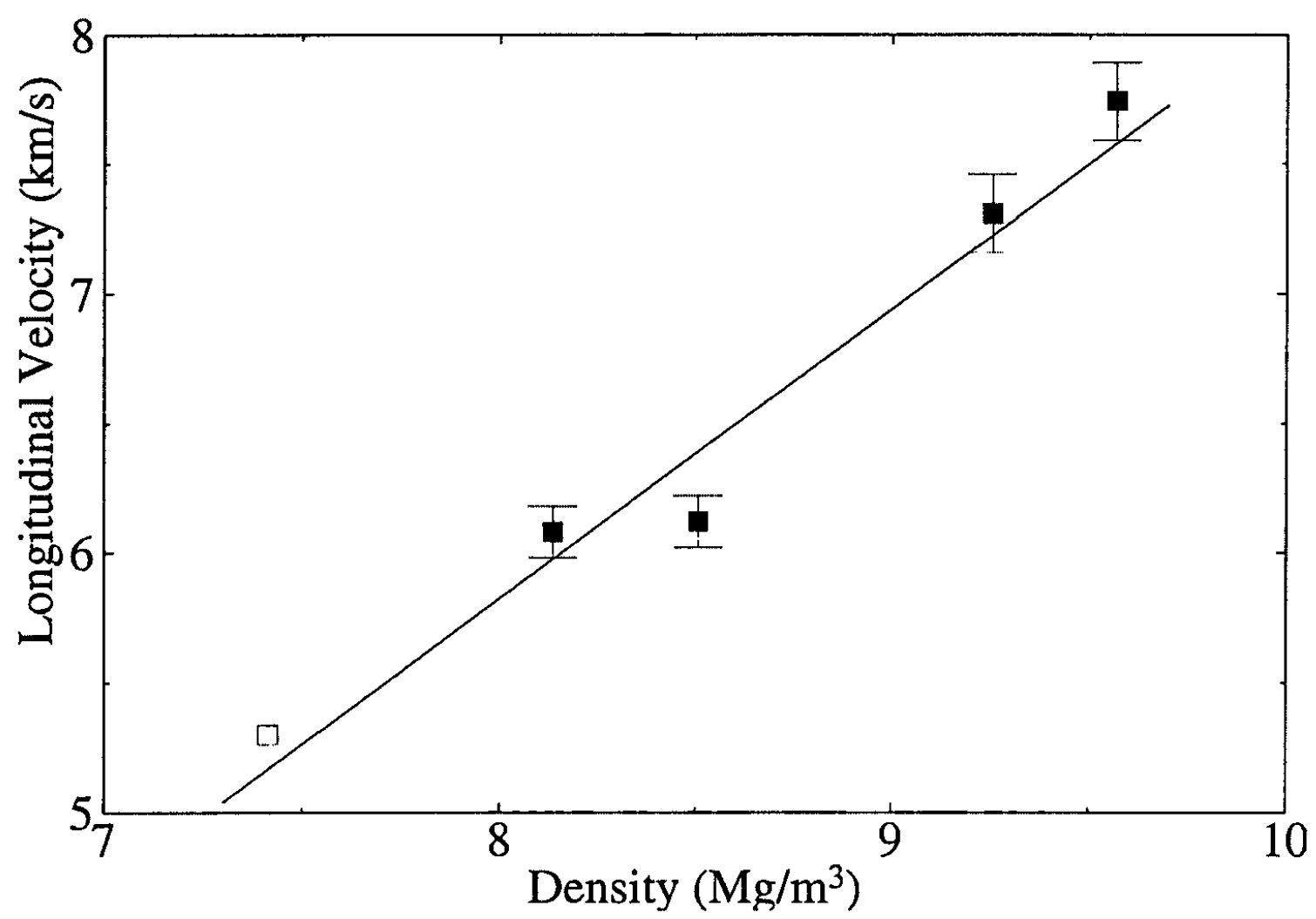

Figure 10: Longitudinal velocity versus density for shocked $\gamma$-iron initially at $1573 \mathrm{~K}$. Open square is calculated from Boehler et al. [21]; solid squares are from this study. 


\section{GRÜNEISEN PARAMETERS OF THE LIQUID AND $\gamma$-PHASE}

From our linear relationship between shock-wave velocity $u_{s}$ and particle velocity $u_{p}$ (Equation 1), the Grüneisen parameter $\gamma$ for liquid iron can be calculated from the bulk sound velocity $V_{b}$ using $[3]$;

$$
\gamma=\frac{\rho_{0}\left[1+s \eta+R^{* 2}(s \eta-1)\right]}{\rho s \eta^{2}}
$$

where $\eta=u_{p} / u_{s}, R^{*}=\rho V_{b} /\left(\rho_{0} u_{s}\right)$. This equation was derived by noting:

$$
\left(\frac{\partial E}{\partial P}\right)_{V}=\frac{(\partial E / \partial V)_{H}-(\partial E / \partial V)_{s}}{(\partial P / \partial V)_{H}-(\partial P / \partial V)_{s}},
$$

where the subscripts $\mathrm{H}$ and $\mathrm{S}$ indicate the derivatives are evaluated along the Hugoniot and the isentrope, respectively. The Rankine-Hugoniot relations are used for evaluating the derivatives to yield Equation 18.

The present value of $V_{b}=6.55 \mathrm{~km} / \mathrm{sec}$ yields $\gamma=1.63 \pm 0.28$ at $\rho=9.37 \pm 0.02 \mathrm{Mg} / \mathrm{m}^{3}$, and

Table V: Thermodynamic Grüneisen parameters for liquid iron

\begin{tabular}{c|c|c|c}
\hline $\mathrm{P}(\mathrm{GPa})$ & $\rho\left(\mathrm{Mg} / \mathrm{m}^{3}\right)$ & $\gamma$ & Reference \\
\hline $10^{-4}$ & $7.019(0.002)$ & $1.72(0.11)$ & {$[33]$} \\
\hline 0.2 & 5.5 & $1.34(0.27)$ & {$[34]$} \\
\hline 0.2 & 6.0 & $1.55(0.31)$ & {$[34]$} \\
\hline 0.2 & 6.5 & $1.75(0.35)$ & {$[34]$} \\
\hline $71.6(1.0)$ & $9.37(0.02)$ & $1.63(0.28)$ & This study \\
\hline $277.4(18.4)$ & $12.64(0.35)$ & $1.42(0.27)$ & {$[13]$} \\
\hline $331.5(9.4)$ & $13.02(0.08)$ & $1.40(0.27)$ & {$[13]$} \\
\hline $397.1(10.2)$ & $13.42(0.08)$ & $1.30(0.27)$ & {$[13]$} \\
\hline
\end{tabular}

is comparable with Brown and McQueen [3]'s data of $\gamma \sim 1.5$ for liquid iron in the density range of 12 to $14 \mathrm{Mg} / \mathrm{m}^{3}$, and Hixson et al. [34]'s liquid iron data between 5.5 and $6.5 \mathrm{Mg} / \mathrm{m}^{3}$ (Table V, Figure 11). The present result yields $\gamma \rho=15.2 \pm 2.6 \mathrm{Mg} / \mathrm{m}^{3}$, which is within the bounds of Brown and McQueen [13] (13.3-19.6 $\left.\mathrm{Mg} / \mathrm{m}^{3}\right)$.

Since the longitudinal sound velocity $V_{p}$ is measured for the solid $\gamma$-phase, equation 18 cannot be used unless the Poisson's ratio $v$ is known and $V_{b}$ can be derived from $V_{p}$ (Equation 11). Poisson's ratio is strongly dependent on pressure and has been modeled in Falzone and Stacey [35]. However, we found the value of $\gamma$ varies drastically with small changes in $v$. Therefore, estimating the variation of the $\gamma$-phase Grüneisen parameter with pressure is not attempted. 


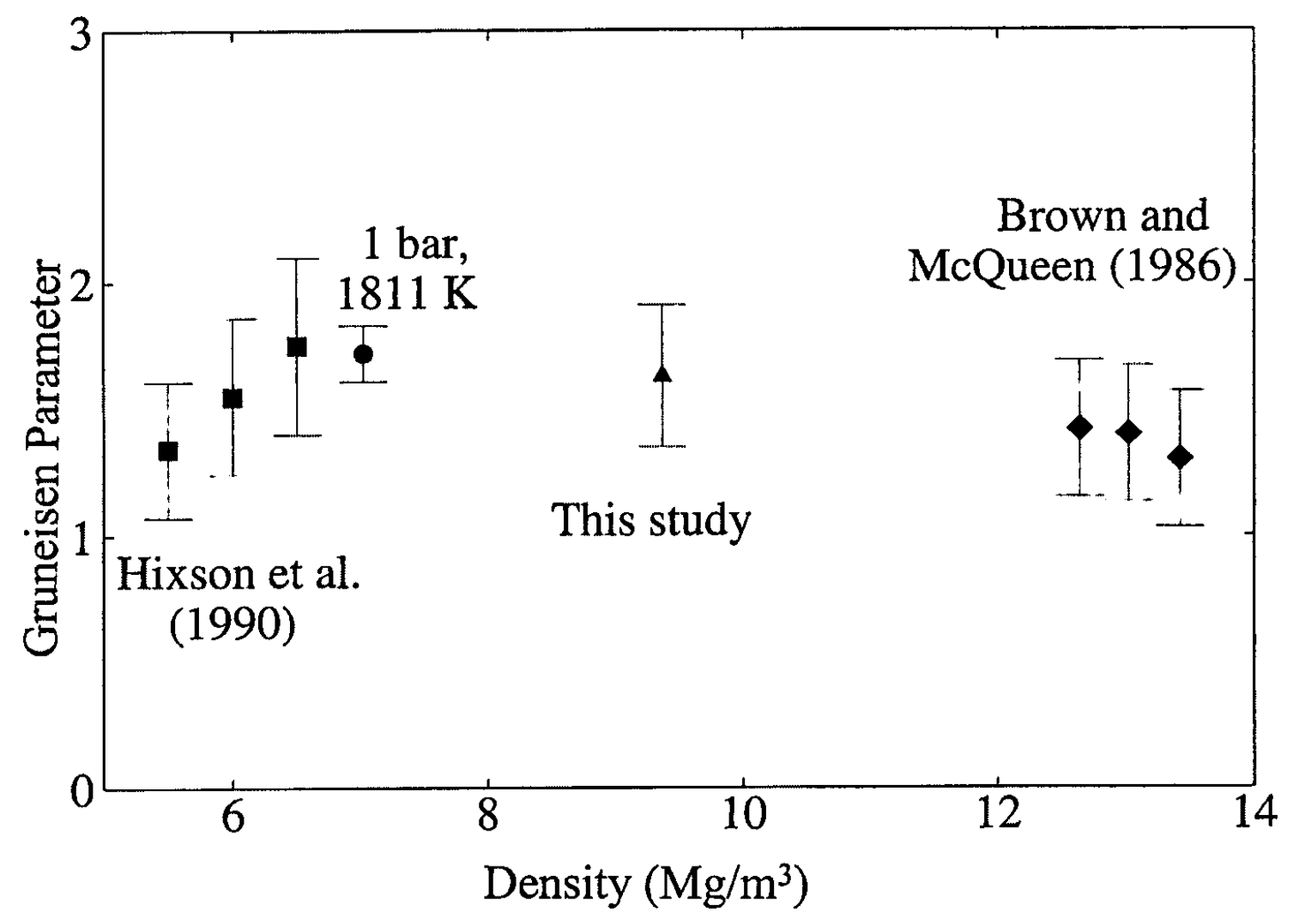

Figure 11: Thermodynamic Grüneisen parameter $\gamma$ for liquid iron versus density. The $1 \mathrm{bar}, 1811$ $\mathrm{K}$ datum is from Anderson and Ahrens [33].

\section{CONCLUSIONS AND APPLICATION TO THE EARTH'S CORE}

Preheated EOS and VISAR experiments are proven to be techniques to obtain absolute values of sound velocities in the $\gamma$-and liquid-phases and hence determine the occurance of the melting of iron. Our data suggest that $\gamma$-iron preheated to $1573 \mathrm{~K}$ upon shock compression melts at $70 \pm 2 \mathrm{GPa}$ and $2775 \pm 160 \mathrm{~K}$.

Experimental results are compatible with Saxena et al. [2] and phase and Boehler [1]'s melting data. The Grüneisen parameter for liquid-phase at $71.6 \mathrm{GPa}$ is determined to be $1.63 \pm 0.28$.

Based on extrapolation of Boehler [1]'s melting data, and using the present molten iron value for $\gamma$ in the Lindemann relation, we estimate the $320 \mathrm{GPa}$ pressure of the inner core-outer core boundary temperature to be $5500 \pm 400 \mathrm{~K}$, and the core-mantle temperature on the outercore side is $\sim 3930 \pm 630 \mathrm{~K}$, assuming adiabaticity of the molten core. These values are $\sim 1200^{\circ}$ lower than previously estimated from shock wave data (4). 


\section{ACKNOWLEDGMENTS}

Research supported by NSF. We thank E. Gelle, M.Long, and A. Devora for experimental assistance. Contribution \#8495, Division of Geological and Planetary Sciences, California Institute of Technology, Pasadena, California.

\section{REFERENCES}

[1] R. Boehler, Temperatures in the Earth's core from melting-point measurements of iron at high pressures, Nature, 363, 534-536, 1993.

[2] S.K. Saxena, G. Shen and P. Lazor, Experimental evidence for a new iron phase and implications for Earth's core, Science, 260, 1312-1314, 1993.

[3] J.M. Brown and R.G. McQueen, Phase transitions, Grüneisen parameter, and elasticity for shocked iron between $77 \mathrm{GPa}$ and $400 \mathrm{GPa}$, J. Geophys. Res., 91, 7485-7494, 1986.

[4] Q. Williams, R. Jeanloz, J. Bass, B. Svendsen and T.J. Ahrens, The melting curve of iron to 250 Gigapascals: A constraint on the temperature at Earth's center, Science, 236, 181$182,1987$.

[5] L.M. Barker and R.E. Hollenbach, Shock wave study of the $\alpha-\varepsilon$ transition in iron, J. Appl. Phys., 45, 4872-4887, 1974.

[6] G.Q. Chen and T.J. Ahrens, Radio Frequency Heating Coils for Shock Wave Experiments, in 1997 Fall Meeting Symposium Proceedings, submitted, 1998.

[7] S.M. Rigden, T.J. Ahrens and E.M. Stolper, Shock compression of molten silicates: Results for a model basaltic composition, J. Geophys. Res., 93, 367-382, 1988.

[8] G.H. Miller, T.J. Ahrens and E.M. Stolper, The equation of state of molybdenum at $1400^{\circ} \mathrm{C}$, J. Appl. Phys., 63, 4469-4475, 1988.

[9] T.S. Duffy and T.J. Ahrens, Dynamic response of molybdenum shock compressed at $1400^{\circ} \mathrm{C}$, J. Appl. Phys., 76, 835-842, 1994.

[10] Y.S. Touloukin (Ed.), Thermophysical Properties of Matter, The TPRC Data Series, Thermal Expansion: Metallic Solids, 12, 1970.

[11] A.C. Mitchell and W.J. Nellis, Shock compression of aluminum, copper, and tantalum, J. Appl. Phys., 52, 3363-3374, 1981.

[12] S.P. Marsh (Ed.), LASL Shock Hugoniot Data, pp. 1-658, University of California Press, Berkeley, 1980.

[14] A.L. Ruoff, Linear shock-velocity-particle-velocity relationship, J. Appl. Phys., 38, 4976$4980,1967$.

[15] L.M. Barker and R.E. Hollenbach, Laser interferometer for measuring high velocities of any reflecting surface, J. Appl. Phys., 43, 4669-4675, 1972.

[16] L.M. Barker and R.E. Hollenbach, Shock-wave studies of PMMA, fused silica, and sapphire, J. Appl. phys., 41, 4208-4226, 1970. 
[17] T.S. Duffy, 1992. Elastic properties of metals and minerals under shock compression, Ph.D. thesis, 298 pp., California Institute of Technology, Pasadena, CA.

[18] D.R. Lide, Handbook of Chemistry and Physics, Vol. 74th Edition, edited by 4-70, CRC Press, Boca Raton, Florida, 1993-1994.

[19] P.M. Nasch, M.H. Manghnani and R.A. Secco, Sound-velocity measurements in liquidiron by ultrasonic interferometry, J. Geophys. Res., 99, 4285-4291, 1994.

[20] C.S. Yoo, J. Akella, A.J. Campbell, H.K. Mao and R.J. Hemley, Phase diagram of iron by in-situ X-ray diffraction: implications for Earth's core, Science, 270, 1473-1475, 1995.

[21] R. Boehler, J.M. Besson, M. Nicol, M. Nielsen, J.P. Itie, G. Weill, S. Johnson and F. Grey, X-ray diffraction of $\gamma$-iron at high temperatures and pressures, J. Appl. Phys., 65, 1795-1797, 1989.

[22] A.B. Belonoshko, Atomic simulation of shock wave-induced melting in argon, Science, 275, 955-957, 1997.

[23] S.K. Saxena, L.S. Dubrovinsky, P. Häggkvist, Y. Cerenius, G. Shen and H.K. Mao, Synchrotron X-ray study of iron at high-pressure and temperature, Science, 269, 1703$1704,1995$.

[24] E. Huang, W.A. Bassett and P. Tao, Pressure-temperature-volume relation for hexagonal close packed iron determined by synchrotron radiation, J. Geophys. Res., 92, 8129-8235, 1987.

[25] R. Boehler and J. Ramakrishnan, Experimental results on the pressure dependence of the Grüneisen parameter: a review, J. Geophys. Res., 85, 6996-7002, 1980.

[26] R.G. McQueen, S.P. Marsh, J.W. Taylor, J.N. Fritz and W.J. Carter, The equation of state of solids from shock wave studies, in: High-Velocity Impact Phenomena, edited by R. Kinslow, pp. 249-419, Academic Press, New York, 1970.

[27] R.A. Robie, B.S. Hemingway and J.R. Fisher, Thermodynamic properties of minerals and related substances at $298.15 \mathrm{~K}$ and 1 bar $\left(10^{5}\right.$ pascals $)$ pressure and at higher temperatures, U.G.S.G. Bulletin, 1452, 456, 1979.

[28] Y.S. Touloukian, R.K. Kirby, R.E. Taylor and P.D. Desai, Thermal expansion of metallic elements and alloys, 208-218 pp., Plenum, New York, 1970.

[29] S.K. Saxena, L.S. Dubrovinsky and P. Häggkvist, X-ray evidence for the new phase betairon at high-temperature and high-pressure, Geophys. Res. Lett., 23, 2441-2444, 1996.

[30] J.M. Brown and R.G. McQueen, The equation of state for iron and the earth's core, in: High Pressure Research in Geophysics, edited by S. Akimoto and M. H. Manghnani, pp. 611622, Academic Press, New York, 1982.

[31] K.G. Holland, 1997. Phase Changes and Transport Properties of Geophysical Materials under Shock Loading, Ph.D. thesis, California Institute of Technology, Pasadena, California.

[32] D.A. Boness, J.M. Brown and J.W. Shaner, Rarefaction velocities in shocked lead, in: Shock Waves in Condensed Matter -1987, edited by S. C. Schmidt and N. C. Holmes, pp. 115-118, North-Holland, New York, 1988. 
[33] W.W. Anderson and T.J. Ahrens, An equation of state for liquid iron and implications for the Earth's core, J. Geophys. Res., 99, 4273-4284, 1994.

[34] R.S. Hixson, M.A. Winkler and M.L. Hodgdon, Sound speed and thermophysical properties of iron and nickel, Phys. Rev. B, 42, 6485-6491, 1990.

[35] A.J. Falzone and F.D. Stacey, Second-order elasticity theory: explanation for the high Poisson's ratio of the inner core, Phys. Earth Planet. Int., 21, 371-377, 1980. 